\title{
An Experimental Model on Multiple Regression Analysis in CMJ and SJ Jump Tests on 10 -14 Years Old Players of Tirana Football Club
}

\author{
Aida Bendo*, Ferdinand Mara \\ Department of Health and Movement, Faculty of Physical Activity and Recreation, Sports University of Tirana, Albania
}

Received August 4, 2020; Revised October 6, 2020; Accepted October 19, 2020

\section{Cite This Paper in the following Citation Styles}

(a): [1] Aida Bendo, Ferdinand Mara , "An Experimental Model on Multiple Regression Analysis in CMJ and SJ Jump Tests on 10 -14 Years Old Players of Tirana Football Club," International Journal of Human Movement and Sports Sciences, Vol. 8, No. 5, pp. 292 - 297, 2020. DOI: 10.13189/saj.2020.080518.

(b): Aida Bendo, Ferdinand Mara (2020). An Experimental Model on Multiple Regression Analysis in CMJ and SJ Jump Tests on 10 -14 Years Old Players of Tirana Football Club. International Journal of Human Movement and Sports Sciences, 8(5), 292 - 297. DOI: 10.13189/saj.2020.080518.

Copyright@2020 by authors, all rights reserved. Authors agree that this article remains permanently open access under the terms of the Creative Commons Attribution License 4.0 International License

\begin{abstract}
In vertical jump performance, the goal of the task is simply to jump as high as possible. In many sports, the height at which an athlete can jump is often of critical importance, as well as the maximal force applied during the vertical jump. In the absence of resistance to air and other external forces, the projection of the center of gravity COG of the whole body is completely determined by the vertical velocity at the moment of takeoff and the acceleration due to gravity. However, this quality does not fully describe the full jump and height achieved. This study aims to use the multiple regression method in both CMJ and SJ vertical jump tests, to understand whether vertical jump performance for Hmax and Fmax respectively parameters, can be predicted based on anthropometric variables such as: age, height, and body mass, as well as biomechanical variables such as: vmax, F.tot.rel, EFI and efficiency. Multiple regression method allows to determine the overall fit of the model and the relative contribution of each of predictor to the total variance explained. The equations of regression for this team emerged these parameters as the best predictor of the main variables for each test: for Hmax in CMJ test: vmax and body mass; and for Fmax in SJ test: body mass and Pmax $/ \mathrm{kg}$.
\end{abstract}

Keywords Counter Movement Jump, Squat Jump, Multiple Regression Analysis

\section{Introduction}

Locomotion and neuromuscular function are important factors in understanding and assessing motor performance. The assessment of motor function through jumping movements using force plate measurements are used as an indicator of motor function, [5]. Vertical jump ability is required for success in a number of sports [4]. A study has found that the ability to generate lower body power is a key component for success in many sport activities [7]. There are a variety of strength training methods that are used to develop athletic performance [12], such as sprinting and jumping. Strength training exercises can be classified as general, special or specific, depending on their biomechanical structure and effect on the neuromuscular system, as reported in studies some studies [3; 4]. Applied to the vertical jump, general strength training exercises are those that are aimed at increasing the maximal strength of the muscles involved in jumping [4]. Vertical jump performance is dependent on contractile properties of muscle as well as the augmentation to the concentric work that occurs due to the stretch shorten cycle, as is shown by some studies [5; 8]. A vertical jump that is preceded by a rapid SSC cycle is called a countermovement jump (CMJ), as opposed to a jump that is not immediately preceded by a prestretch, for example a squat jump (SJ) [4]. The usage of arms during a CMJ has been shown to increase takeoff velocity, ground reaction force (GRF) and the height of the 
center of gravity (COG) prior to takeoff [11]. Various types of strength-training modalities have been utilized in order to improve lower body power as can be measured by vertical jump [7]. Body weigh jumping refers exclusively to non-weighted lower body plyometric exercises, such as squat, countermovement and drop jumps. Body weight jump is also highly practical, because it requires little or no equipment, and can be performed in almost any location and requires limited technical ability [1]. Some studies have shown that both the individual plyometric and weight training programs increased vertical jump performance, but the combination program showed the greatest improvement of vertical jump performance, [2; 5; 10].

The application of the laws of physics to human movement allows a scientific description of this motion. According to the second Newton's law, the ground reaction force $F_{z}(t)$ and the body weight are related to the vertical accelerating during vertical jump as follow:

$$
\sum F_{Z}=m \frac{d v_{z}}{d t}=F_{Z}(t)-m g
$$

So, the velocity at takeoff phase is given as:

$$
v_{t_{0}}=\frac{1}{m} \int_{t_{1}}^{t_{2}}\left[F_{Z}(t)-m g\right] d t
$$

Based on the energy conservation law, the mechanical energy of the COG in the peak of height can be expressed:

$$
E_{K_{t_{0}}}+E_{P_{t_{0}}}=E_{K_{h}}+E_{P_{h}}
$$

Solving the equation the vertical velocity at takeoff is related to the jumping height as follows:

$$
H_{\text {jump }}=-\left(\frac{v_{\text {take-off }}^{2}}{2 g}\right)
$$

Some studies have found that jumping ability can be improved in several methods [4;5], which includes general and specific exercises.

\section{Material and Methods}

The participating subjects were taken from Tirana football club team, through the application of test measurements performed on a force plate Leonardo Mechanograpy GRF [9], at the Sports University of Tirana, in Biomechanics laboratory. Subjects participating in were 29 boys aged 10-14, mean (12.1 \pm 0.62$)$ years old. Informed consent was obtained from the parents of subjects, in order to consider them as participants of the study. The subjects were tested in two forms: CMJ (counter movement jump) test - test for maximal height, performed with arm swing, and SJ (squat jump) test- test for maximal force, jump without arm swig with arms closed to the waist. The study period includes three phases. The study period includes three phases. The initial phase: before training measurements, middle: after six months and the final phase: nine months after training measurements. The program was based on combined general and specific strength training improving maximal jump height and maximal output strength training which included: plyometric, izokinetic and kinetic chanin exercises. Statistical analyses were performed using SPSS version 20. During the processing of the results, multilpe regression method was used. This method allows to determine the overall fit of the model and the relative contribution of each of predictor to the total variance explained. Statistical significance was set for all statistical procedures at $\mathrm{p} \leq 0.05$.

\section{Results}

Table 1 gives the descriptive statistics of the anthropometric parameters and generates also the variables obtained during the three measurements of CMJ and SJ test, which are used to find the best predictor in multiple regression analysis. 
Table 1. Statistical descriptive of anthropometric parameters and variables on three different phases of CMJ and SJ tests

\begin{tabular}{|c|c|c|c|c|c|c|c|}
\hline \multicolumn{2}{|c|}{ Measurement } & Parameter & Mean \pm SD & Rank & Min. Value & Max. Value & Variance \\
\hline \multirow{4}{*}{\multicolumn{2}{|c|}{$\begin{array}{l}\text { Anthropometric } \\
\text { characteristics }\end{array}$}} & Age (years old) & $12.10 \pm 0.62$ & 4.00 & 10.00 & 14.00 & 0.38 \\
\hline & & Height (m) & $1.54 \pm 0.94$ & 0.40 & 1.36 & 1.76 & 0.01 \\
\hline & & Body mass (kg) & $46.55 \pm 9.74$ & 38.40 & 31.90 & 70.30 & 94.81 \\
\hline & & BMI $\left(\mathrm{kg} / \mathrm{m}^{2}\right)$ & $19.30 \pm 2.37$ & 8.71 & 15.58 & 24.29 & 5.63 \\
\hline \multirow{9}{*}{ CMJ test } & \multirow{3}{*}{ Phase I } & H1max (m) & $0.37 \pm 0.05$ & 0.21 & 0.27 & 0.48 & 0.003 \\
\hline & & V1max. (m/s) & $2.31 \pm 0.17$ & 0.73 & 1.87 & 2.60 & 0.03 \\
\hline & & E.F.I.1 & $102.03 \pm 14.25$ & 50.00 & 75.00 & 125.00 & 203.03 \\
\hline & \multirow{3}{*}{ Phase II } & H2max (m) & $0.42 \pm 0.57$ & 1.16 & 0.33 & 0.49 & 0.003 \\
\hline & & V2max. (m/s) & $2.40 \pm 0.15$ & 0.50 & 2.14 & 2.64 & 0.02 \\
\hline & & E.F.I.2 & $109.38 \pm 10.95$ & 35.00 & 92.00 & 127.00 & 119.96 \\
\hline & \multirow{3}{*}{ Phase III } & H3max (m) & $0.45 \pm 0.05$ & 1.21 & 0.35 & 0.56 & 0.003 \\
\hline & & V3max. (m/s) & $2.51 \pm 0.13$ & 0.56 & 2.23 & 2.79 & 0.02 \\
\hline & & E.F.I.3 & $114.97 \pm 10.26$ & 36.00 & 100.00 & 136.00 & 105.25 \\
\hline \multirow{6}{*}{ SJ test } & \multirow{2}{*}{ Phase I } & F1max (kN) & $1.07 \pm 0.25$ & 0.97 & 0.69 & 1.66 & 0.06 \\
\hline & & P1max./kg & $37.66 \pm 4.13$ & 14.60 & 29.04 & 43.64 & 17.02 \\
\hline & \multirow{2}{*}{ Phase II } & F2max (kN) & $1.19 \pm 0.27$ & 1.16 & 0.81 & 1.97 & 0.07 \\
\hline & & P2max./kg & $40.14 \pm 4.32$ & 16.46 & 30.48 & 46.94 & 18.64 \\
\hline & \multirow{2}{*}{ Phase III } & F3max (kN) & $1.40 \pm 0.28$ & 1.15 & 0.97 & 2.12 & 0.08 \\
\hline & & P3max./kg & $41.58 \pm 4.55$ & 17.45 & 31.08 & 48.53 & 20.72 \\
\hline
\end{tabular}

\subsection{Results of Multiple Regression to the First CMJ Test}

In the first CMJ test, the multiple regression method is used to understand if the performance of vertical jump test to measure the maximum height $(H \max )$ can be predicted based on anthropometric variables such as age, body height, body mass and also in the biomechanics variables as maximum velocity (Vmax), the total relative strength (F.tot.rel), Esslinger Fitness Index (EFI) and efficiency of movement.

\subsection{Adjusting the Overall Model}

Multiple regression methods allow determining the overall fit of the model and the relative contribution of each predictor in complete variance to explain. At CMJ test should be known the percentage of variation of test performance on the dependent variable (Hmax) that can be explained by anthropometric and biomechanics parameters as a whole, but also the "relative contribution" of each of the independent variables in explaining variance. By application of the method of multiple regression for the anthropometric and biomechanical data obtained for the first CMJ test, table 2 is generated.

Table 2 gives a summary overview of the model. $\rightarrow R$ value represents the coefficient of multiple correlations. $\mathrm{R}$ can be considered to be a measure of predict quality (Hmax). A value of $\mathrm{R}=0.742$ in this case shows a good level of prediction. Value $\mathrm{R}^{2}$ is also the coefficient of determination, which is part of the variance in the dependent variable that can be explained by the independent variables; values $\mathrm{R}^{2}=0.555$ shows that independent variables taken on this model can explain 55\% of the variance of the variable independent, so Hmax.

Table 2. Summary of the overall model.

\begin{tabular}{|c|c|c|c|c|}
\hline Model & $\mathrm{R}$ & R Square & $\begin{array}{c}\text { Adjusted R } \\
\text { Square }\end{array}$ & $\begin{array}{c}\text { Std. Error of the } \\
\text { Estimate }\end{array}$ \\
\hline 1 & $.742^{\mathrm{a}}$ & .550 & .428 & .03944 \\
\hline
\end{tabular}
Vmax.

$\mathrm{R}^{2}$ value adjusted is used to report and accurately interpret the model as a whole, then $\mathrm{R}^{2}=0.428$ vale adjusted accurately explains $42.8 \%$ of the variance of Hmax in the CMJ test.

In the Anova table, value F Fisher test whether the full regression model fits well with the data. For this parameter, the value of Fischer's, $F(6,22)=4.490$ and $p=$ 0.004. $\mathrm{p}<0.050$ means that the regression model fits well with the data.

\subsection{CMJ Test- The Model Coefficient Calculation}

The regression coefficients table offers the information needed to predict the dependent variable (Hmax) by independent anthropometric and biomechanics variables as well as to determine the statistical model significance 
(based on the value of the column $t$ and sig column. value p). Based on beta coefficients ( $\beta$ ), the general form of Regression equations for predicting Hmax is:

$$
\begin{gathered}
H_{\max }(\text { predicted })=y=-0.214+0.001(\text { Age })+ \\
+0.055(\text { Body length })-0.002(\text { Body mass })+ \\
+0.26\left(v_{\max }\right)-0.011(\text { EFI })
\end{gathered}
$$

This equation gives an analysis of the overall prediction, but provides no information on the best predictors. The coefficient table also tests for statistical significance of each of the independent variables, so it tests if the coefficients are equal to zero in the population. Exploratory study provides information on which independent variables are the most important and best predictors of the regression model.

\subsection{Finding the Best Models on CMJ Test}

Table 3 provides a summary of exploratory models, indicating which variables are included in the model step by step.

Table 3. Summary exploratory model

\begin{tabular}{|c|c|c|c|c|}
\hline Model & $\mathrm{R}$ & R Square & $\begin{array}{c}\text { Adjusted } \\
\text { R Square }\end{array}$ & $\begin{array}{c}\text { Std. Error of the } \\
\text { Estimate }\end{array}$ \\
\hline 1 & $.673^{\mathrm{a}}$ & .452 & .432 & .03929 \\
\hline 2 & $.735^{\mathrm{b}}$ & .541 & .505 & .03667 \\
\hline
\end{tabular}

a. Predictors: (Constant), Vmax

b. Predictors: (Constant), Vmax, body mass

According to the model A) $\rightarrow \mathrm{Vmax}$ is the best predictor alone. For this variable, $\mathrm{R}=0.673, \mathrm{R}^{2}=0452$ and the first step estimates $45.2 \%$ of the variance of the independent variable. $\mathrm{F}$ and $\mathrm{p}$ value reported by Anova are: $\mathrm{F}(1,27)=$ 22,314, $\mathrm{p}<0.001$

According to the model B), Vmax and body mass are the best predictor model. So, body mass is the second best predictor and added after Vmax and which is included in the model. For both variables, $\mathrm{R}=0.735, \mathrm{R}^{2}=0.541$ and the second step calculates the $54.1 \%$ of the variance of the two respective variables. The corresponding values are: $F(2,26)=15,308 ; p<0.001$.

Both models together have significant results, since both of them $\mathrm{p}<0.001$.

\subsection{Results of Multiple Regression to the Second SJ Test}

In the second SJ test, the multiple regression method is used to understand if the performance of the vertical jump test to measure the maximum force (Fmax) can be predicted based on the anthropometric variables such as: age, body height, body mass and also on the biomechanical variables such as: maximum vertical jump height (Hmax), maximum velocity (Vmax), Esslinger Fitness Index (EFI) and efficiency of movement.

\subsection{Finding the Best Model on SJ Test}

A summary of exploratory models indicating which variables are included in the model step by step is shown in table 4.

Table 4. Summary of exploratory model.

\begin{tabular}{|c|c|c|c|c|}
\hline Model & $\mathrm{R}$ & R Square & $\begin{array}{c}\text { Adjusted } \\
\text { R Square }\end{array}$ & $\begin{array}{c}\text { Std. Error of the } \\
\text { Estimate }\end{array}$ \\
\hline 1 & $.497^{\mathrm{a}}$ & .247 & .219 & .24565 \\
\hline 2 & $.594^{\mathrm{b}}$ & .353 & .303 & .23215 \\
\hline
\end{tabular}

a. Predictors: (Constant), Body mass

b. Predictors: (Constant), Body mass; Pmax/kg

According to the model A), $\rightarrow$ Body mass is the best predictor alone. For this variable, $\mathrm{R}=0.497, \mathrm{R}^{2}=0.247$ and the first step estimates $24.7 \%$ of the variance for the independent variable. $\mathrm{F}(1,27)=8.58$ and $\mathrm{p}=0.006$.

According to the model B), Body mass and Pmax $/ \mathrm{kg}$ are the best predictors model. So Pmax $/ \mathrm{kg}$ is the second best predictor added after body mass and that was included in the model. For both variables, $\mathrm{R}=0594, \mathrm{R}^{2}=0353$ and the second step calculates $35.3 \%$ of the variance of these two variables. $\mathrm{F}(2,26)=7079$ and $\mathrm{p}=0.00$.

Both models together have significant results, since for both models $\mathrm{p}<0.050$.

\section{Discussion}

\subsection{The Regression Equation for the Best Predictors on CMJ test}

The beta coefficients array ( $\beta$ ) gives the corresponding values for a better predictor model; therefore, based on them regression equation can be constructed. Table 5 noted that $\beta$ coefficients vary depending on the predictors are included in the model.

Table 5. Beta coefificients on CMJ test.

\begin{tabular}{|c|c|c|c|c|c|c|}
\hline \multicolumn{7}{|c|}{ Coefficients $^{\mathrm{a}}$} \\
\hline \multirow{2}{*}{ Model } & $\begin{array}{c}\text { Unstandardized } \\
\text { Coefficients }\end{array}$ & $\begin{array}{c}\text { Standardized } \\
\text { Coefficients }\end{array}$ & \multirow{2}{*}{ t } & \multirow{2}{*}{ Sig. } \\
\cline { 3 - 8 } & B & Std. Error & Beta & & \\
\hline \multirow{2}{*}{1} & (Constant) & -.220 & .142 & & -1.544 & .134 \\
\cline { 2 - 8 } & Vmax & .267 & .057 & .673 & 4.724 & .000 \\
\hline \multirow{3}{*}{2} & (Constant) & -.193 & .133 & & -1.445 & .160 \\
\cline { 2 - 8 } & Vmax & .286 & .053 & .721 & 5.354 & .000 \\
\cline { 2 - 7 } & Body mass & -.002 & .001 & -.301 & -2.235 & .034 \\
\hline
\end{tabular}

a. Dependent Variable: Hmax.

The regression equations for both models involved in exploratory study are as follows: 


\section{Equation according to the model A)}

$$
Y=-0.22+0.267\left(\mathrm{v}_{\max }\right)
$$

This is the weight of an equation that includes: Vmax as the best predictors of this model. According to this equation, for any speed increase of $1 \mathrm{~m} / \mathrm{s}$ there is an increase of Hmax with $0.267 \mathrm{~m}$ or $26.7 \mathrm{~cm}$.

\section{Equation according to the model $B$ )}

$$
Y=-0.193+0.286\left(\mathrm{v}_{\max }\right)-0.002 \text { (Body mass) }
$$

These are the weights for an equation that includes: Vmax and body mass as the best predictors of this model. According to this model, for any increase in speed of $1 \mathrm{~m} / \mathrm{s}$ there is an increase of Hmax with $0.002 \mathrm{~m}$ or $0.2 \mathrm{~cm}$. From the inverse analysis, very small changes of $\mathrm{R}^{2}$ between the initial step and exploratory study are seen, and this is why models A and B exclude other predictors as not very important in the regression model.

\subsection{The Regression Equation for the Best Predictors on SJ Test}

Table of beta coefficients ( $\beta$ ) gives the corresponding values for a better predictor model; therefore, based on them, regression equation can be constructed. From Table 6 , it is noted that $\beta$ coefficients vary depending on the predictors are included in the model.

\begin{tabular}{|c|c|c|c|c|c|c|}
\hline \multicolumn{7}{|c|}{ Coefficients $^{\mathrm{a}}$} \\
\hline & \multirow[t]{2}{*}{ Model } & \multicolumn{2}{|c|}{$\begin{array}{c}\text { Unstandardized } \\
\text { Coefficients }\end{array}$} & \multirow{2}{*}{\begin{tabular}{|c|}
$\begin{array}{c}\text { Standardized } \\
\text { Coefficients }\end{array}$ \\
Beta \\
\end{tabular}} & \multirow[t]{2}{*}{$\mathrm{t}$} & \multirow[t]{2}{*}{ Sig. } \\
\hline & & B & Std. Error & & & \\
\hline \multirow{2}{*}{1} & (Constant) & .740 & .227 & & 3.267 & .003 \\
\hline & Body mass & .014 & .005 & .497 & 2.977 & .006 \\
\hline \multirow{3}{*}{2} & (Constant) & -.126 & .473 & & -.268 & .791 \\
\hline & Body mass & .015 & .005 & .526 & 3.322 & .003 \\
\hline & Pmax.kg & .020 & .010 & .326 & 2.057 & .050 \\
\hline
\end{tabular}

Table 6. Beta coefficients on SJ test

Dependent Variable: Fmax.

The regression equations for both models involved in exploratory study are as follows:

Equation according to the model $A$

$$
y=0.74+0.014 \text { (Body mass) }
$$

This is the weight of an equation that includes: body mass as the best predictors of this model. According to this equation, for any increase in body mass of $1 \mathrm{~kg}$ there is also an increase of the Fmax with $0.014 \mathrm{kN}$ or $14 \mathrm{~N}$.

\section{Equation according to the model $B$ )}

$$
y=-0.126+0.015 \text { (Body mass })+0.02\left(\mathrm{P}_{\max } / \mathrm{kg}\right)
$$

These are the weights for an equation that includes: Body mass P.max $/ \mathrm{kg}$ as the best predictors of this model.
According to this model, for any increase in body mass of $1 \mathrm{~kg}$ there is also an increase of Fmax with $0.014 \mathrm{~N}$ and for every $1 \mathrm{Watt} / \mathrm{kg}$ added to Pmax/kg there is an increase of Fmax with $0.02 \mathrm{kN}$, or $20 \mathrm{~N}$.

\section{Conclusions}

Combined general and specific strength training is effective as power training for improving maximal jump height and maximal output in CMJ and SJ tests. The strength exercises develop and improve the psychophysical, coordinative and locomotive condition, enabling the subject to both mentally mobilize and having a higher muscular tonification, by gradually increasing the moving efficiency; and the performance is improved. Multiple regression method applied to CMJ and SJ tests for Tirana futball team allows to determinine the overall fit of the model and the relative contribution of each of predictor to the total variance explained. In both tests, it was found how much of the variation in the test performance of the depended variable can be explained by anthropometric and biomechanical parameters as well as the relative contribution of each independent variable in expaining the variance. Multiple equations of regression for this team emerged these parameters as the best predictor of the main variables for each test: for Hmax in CMJ test: vmax and body mass; and for Fmax in SJ test: body mass and Pmax $/ \mathrm{kg}$. Clearly, the jumping technique strongly affects the mechanical output muscles, as the motors that generate explosion maximal force and also maximal jump height. Finally, all strength exercises in Tirana Football team players have improved the biomechanical parameters, including the sportive technique.

\section{REFERENCES}

[1] Anthony Dormiento, Andrew J. Galphin, Lee Brown. Vertical jump \& power. J. Str. \& Cond. Ass. Vol.34(6); 2012

[2] Asmussen, E, Bonde-Peterson F. Storage of elastic energy in skeletal muscles in man. Acta Physiol Scand; 91: 385-392; 1974

[3] Australian Strength \& Conditioning association level 1, Coaching Course Syllabus, Toowong, Bristone, ASCA, 1993

[4] Baker Daniel. Improving vertical jump performance through general, special and specific strength training, A brief Review, J. Strength \& Cond. Res, 10(2); 131-136; 1996.

[5] Bendo A, Skënderi Dh. "Assessing biomechanical parameters of SUT students through the jumping test”. Journal of Physical Activity \& Sports, vol.2(1); 50-57; 2014

[6] Hrysomallis C. The effectiveness of resisted movement training on sprinting \& jumping performance, J. Strength Cond. Res. (26), 299-306; 2012 
[7] Kevin Carlson, Marshall Magnusen, Peter Walters. Effect of various training modalities on vertical jump, J. Res. Sports Med, vol. 17(2); 84-94; 2009

[8] Komi P \& C. Bosco. Utilization of stored elastic energy in leg extensor muscles of men \& woman, Med. Sci. Sports, (10): 261-265; 1978

[9] Leonardo Mechanograpy Ground Reaction Force Platform (GRFP) v4.2. St. Ed. 2010

[10] Lyttle AD, Wilson GJ \& Ostrowski KJ. Enhancing performance: Maximal power versus combined weights \& plyometrics training. Journal of Strength \& Cond. Res, (10); 173-179; 1996

[11] McBride JM, Triplett-McBride, T. David \& Newton RU, The effect of heavy-vs. height-load jump squats on the development of strength power \& speed. J. of Strength \& Cond. Res, PubMed; (16); 75-82, 2002

[12] Vanderka Marian, Longova Katarina, Olasz David, Krcmar Matus, Walker Simon. Improved maximum strength vertical jump \& spring performance after 8 weeks of jump squat training with individualized loads, Journal of Sports Sci Med. 15(3); 492-500; 2016 